\title{
An assessment of the decomposition kinetics of sulfur-containing biocides to hydrogen sulfide at simulated downhole conditions
}

\author{
Juan J. Marrugo-Hernandez, Rohen Prinsloo and Robert A. Marriott* \\ Department of Chemistry, University of Calgary, Alberta, Canada \\ *Correspondence to: rob.marriott@ucalgary.ca
}

\section{Supplementary Information}

All reagents, unless otherwise noted, were obtained from commercial sources and verified by NMR. Chromatography refers to flash chromatography on silica gel (230-400 mesh). Analytical TLC was carried out on aluminum backed plates coated with Merck silica gel 60 F-254, with detection by UV light. NMR spectra were recorded in deuteriochloroform. Chemical shifts are reported in parts per million (ppm) and referencing of chemical shifts was relative to the residual solvent ( ${ }^{1} \mathrm{H}$ NMR $\left.\delta 7.26 ;{ }^{13} \mathrm{C} \delta 77.16 \mathrm{ppm}\right)$. Assignments of primary, secondary, tertiary, and quaternary carbons, where indicated, were based upon DEPT-135 or HSQC analyses. Structure elucidations were assigned based on DEPT, COSY, HSQC and HMBC spectra. ${ }^{1} \mathrm{H}$ NMR, ${ }^{13} \mathrm{C}$ NMR, DeptQ, Dept135, Cosy, HSQC, HMBC data were collected on a Bruker Avance $400 \mathrm{MHz}$ $\left({ }^{1} \mathrm{H}, 400 \mathrm{MHz},{ }^{13} \mathrm{C}, 101 \mathrm{MHz}\right)$. The following abbreviations were used to designate multiplicities: $\mathrm{s}=$ singlet, $\mathrm{d}=$ doublet, $\mathrm{dd}=$ doublet of doublets, $\mathrm{br}=$ broad singlet.

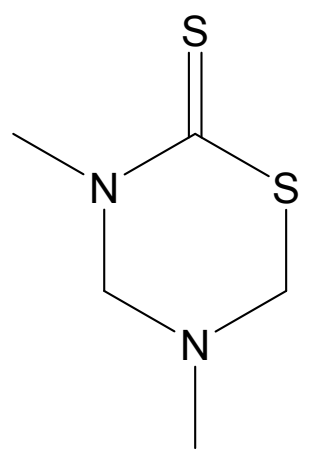

Figure S1. Chemical structure of Dazomet, $\mathrm{C}_{5} \mathrm{H}_{10} \mathrm{~N}_{2} \mathrm{~S}_{2}$, 3,5-Dimethyl-1,3,5-thiadiazinane-2thione. 
A $40 \%$ aqueous solution of methyl amine ( $40 \mathrm{~g}, 0.52$ mols) was added to a round bottom flask and cooled to $15^{\circ} \mathrm{C}$. Carbonyl sulfide $(24.4 \mathrm{~g}, 0.32 \mathrm{mols})$ was added dropwise to the solution and the mixture was stirred for $1 \mathrm{~h}$ while maintaining the temperature below $20^{\circ} \mathrm{C} .37 \%$ formaldehyde $(51.95 \mathrm{~g}, 0.64 \mathrm{mols})$ was added to the reaction flask and the mixture was stirred for $30 \mathrm{~min}$. The white precipitate was filtered and rinsed with distilled water $(3 \times 20 \mathrm{ml})$ to yield $88 \%(45.93 \mathrm{~g}, 0.28$ mols) of the desired product. The product was recrystallised in xylenes yielding white needle shaped crystals. ${ }^{1} \mathrm{H}$ NMR (400 MHz, $\left.\mathrm{CDCl}_{3}\right) \delta 4.36$ (s, 2H), 4.30 (s, 2H), 3.44 (s, 3H), 2.61 (s, $3 \mathrm{H}) .{ }^{13} \mathrm{C} \mathrm{NMR}\left(101 \mathrm{MHz}, \mathrm{CDCl}_{3}\right) \delta 191.4(\mathrm{C}), 73.0\left(\mathrm{CH}_{2}\right), 60.1\left(\mathrm{CH}_{2}\right), 40.4\left(\mathrm{CH}_{3}\right), 39.1\left(\mathrm{CH}_{3}\right)$.

A 10 fold diluted sample of extract was analyzed by using a Bruker Scion-SQGC-MS with a $15 \mathrm{~m}$ $\times 0.25 \mathrm{~mm}$ I.D. BR-5 ms column. GC oven was held at $50{ }^{\circ} \mathrm{C}$ for $1 \mathrm{~min}$ and then increased to $T=$ $320^{\circ} \mathrm{C}$ at a rate of $10^{\circ} \mathrm{C} / \mathrm{min}$. The method has a mass scanning range of 33 to $500 \mathrm{~m} / \mathrm{z}$ and a data acquisition rate of $5 \mathrm{~Hz}$. Mass spectrum (EI, $m / z, \%) 162.02\left[\mathrm{M}^{+}\right]$.

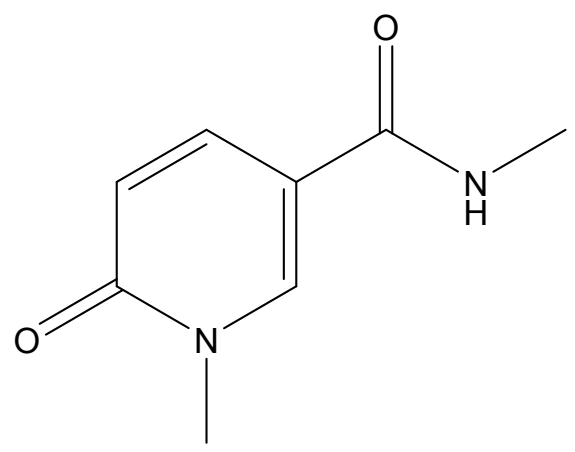

Figure S2. Chemical structure of $\mathrm{C}_{8} \mathrm{H}_{10} \mathrm{~N}_{2} \mathrm{O}_{2}, \quad$, 1-dimethyl-6-oxo-1,6-dihydropyridine-3carboxamide.

The reaction described for decomposition of methylisothiazolinone was performed on a larger scale (1g, 6.02 mols). The aqueous mixture was extracted with chloroform $(3 \times 25 \mathrm{~mL})$, dried with magnesium sulfate and concentrated under vacuum. The crude product was purified by column chromatography on silica gel (4\% $\mathrm{MeOH} / \mathrm{DCM})$ to afford the 3-pyridinecarboxamide as a pale brown precipitate. ${ }^{1} \mathrm{H}$ NMR $\left(400 \mathrm{MHz}, \mathrm{CDCl}_{3}\right) \delta 4.36(\mathrm{~s}, 2 \mathrm{H}), 4.30(\mathrm{~s}, 2 \mathrm{H}), 3.44(\mathrm{~s}, 3 \mathrm{H}), 2.61(\mathrm{~s}$, 3H). ${ }^{1} \mathrm{H}$ NMR $\left(400 \mathrm{MHz}, \mathrm{CDCl}_{3}\right) \delta 8.11(\mathrm{~d}, J=2.6 \mathrm{~Hz}, 1 \mathrm{H}), 7.58(\mathrm{dd}, J=9.5,2.7 \mathrm{~Hz}, 1 \mathrm{H}), 6.17$ 
(br, 1H), $6.51(\mathrm{~d}, J=9.5 \mathrm{~Hz}, 1 \mathrm{H}), 3.58(\mathrm{~s}, 3 \mathrm{H}), 2.96(\mathrm{~d}, 3 \mathrm{H}) .{ }^{13} \mathrm{C} \mathrm{NMR}\left(101 \mathrm{MHz}, \mathrm{CDCl}_{3}\right) \delta 164.8$ (C), $162.9(\mathrm{C}), 141.6(\mathrm{CH}), 136.3(\mathrm{CH}), 119.5(\mathrm{CH}), 113.3(\mathrm{C}), 38.3\left(\mathrm{CH}_{3}\right), 26.9\left(\mathrm{CH}_{3}\right)$.

High resolution mass spectra were obtained by electron impact ionization at $70 \mathrm{eV}$ using a Waters GCT Premier TOF-MS by direct probe sample introduction. Mass spectrum (CI, $m / z) 166.1\left[\mathrm{M}^{+}\right]$, 136.1. HRMS (EI) calc'd for $\mathrm{C}_{8} \mathrm{H}_{10} \mathrm{~N}_{2} \mathrm{O}_{2} 166.0742$ [M+], found 166.0740.

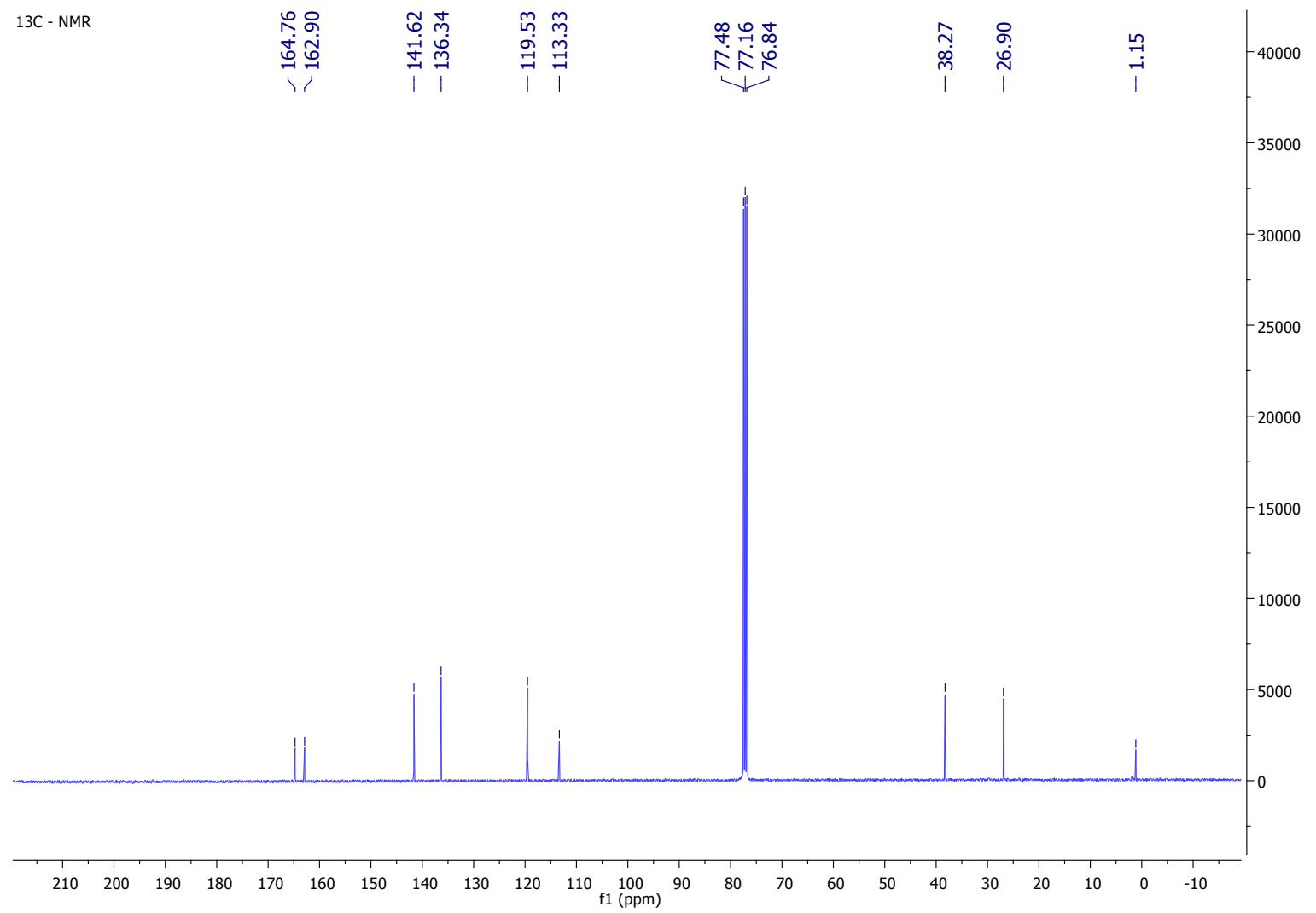

Figure S3. ${ }^{13} \mathrm{C}$ NMR of intermediate 3-pyridinecarboxamide 


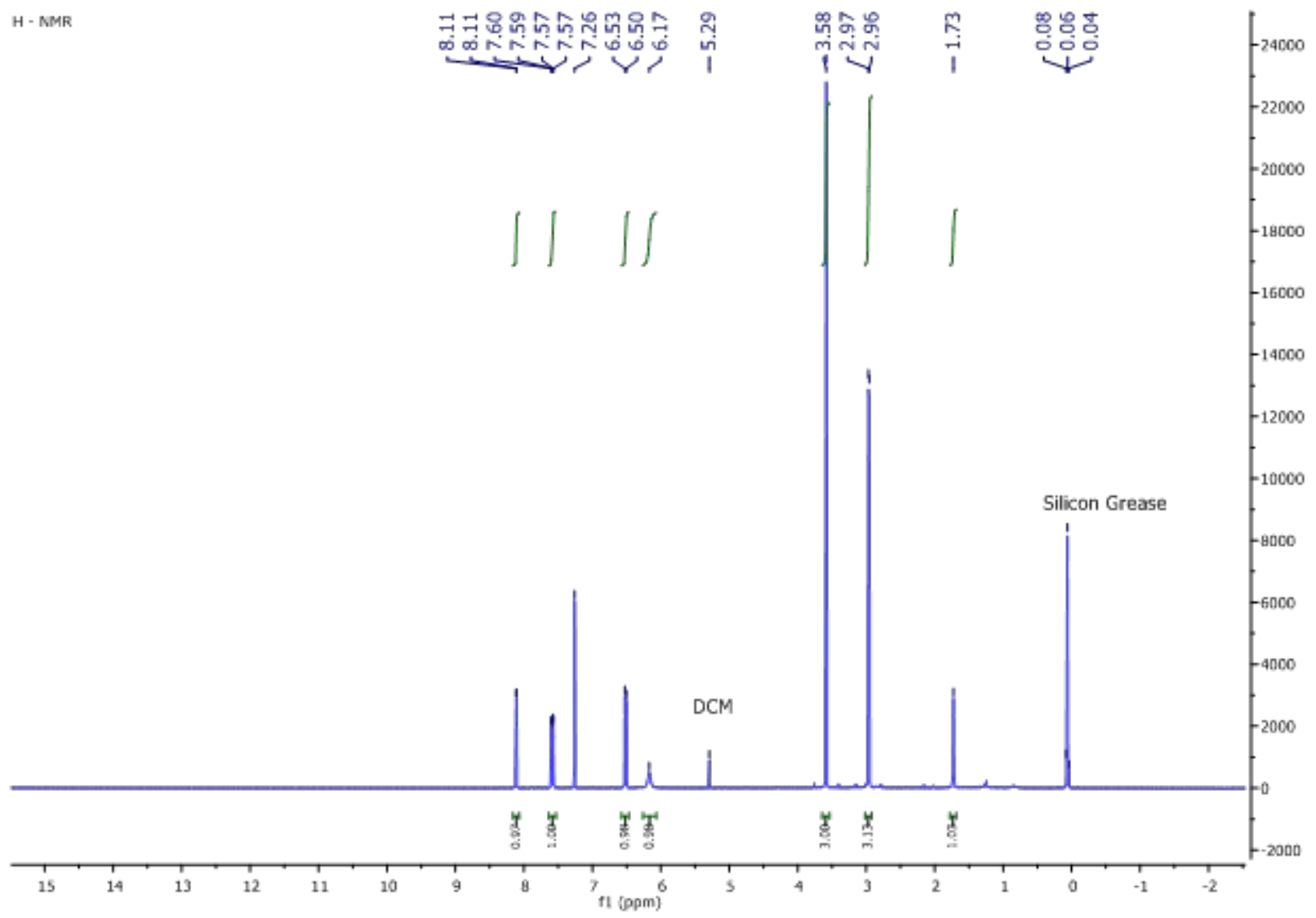

Figure S4. $\mathrm{H}^{1}$ for 3-pyridinecarboxamide

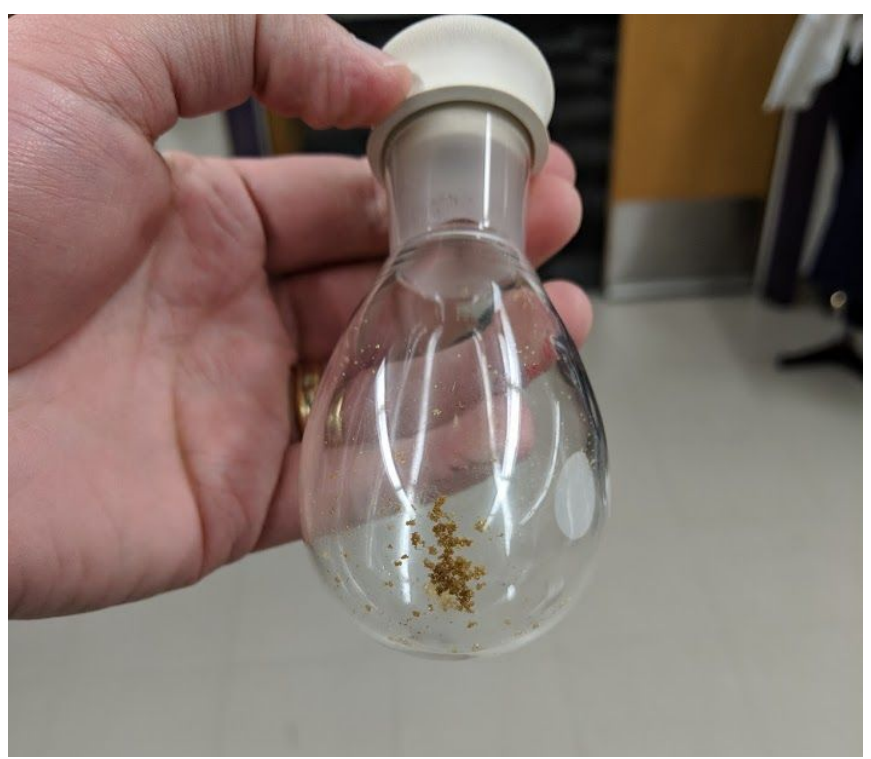

Figure S5. Elemental sulfur extracted from the decomposition of methylisothiazolinone. 